\title{
Sinopsis de la familia Myrtaceae y clave para la identificación de los géneros nativos e introducidos en Colombia
}

\author{
Carlos Parra-O.
}

Instituto de Ciencias Naturales, Universidad Nacional de Colombia, Bogotá, Colombia

\begin{abstract}
Resumen
Se presenta una sinopsis taxonómica de la familia Myrtaceae en Colombia que incluye los géneros nativos e introducidos en el país. Se analiza la diversidad de la familia en términos de la riqueza de especies, la distribución geográfica y altitudinal y la representatividad en las regiones naturales del país. Se describen los caracteres morfológicos que permiten diferenciar los géneros, así como los caracteres diagnósticos de cada uno, la distribución geográfica y una estimación preliminar del número de especies de estos. Se concluye con una clave para la identificación de los géneros de la familia en Colombia.
\end{abstract}

Palabras clave: Colombia, Calyptranthes, Eugenia, flora de Colombia, Myrcia, Myrtaceae.

Synopsis of the plant family Myrtaceae and key for the identification of the native and introduced genera in Colombia

\begin{abstract}
A taxonomic synopsis of Myrtaceae in Colombia is presented, including all native and introduced genera of the family growing in the country. The family diversity is analyzed in terms of species richness, geographic and altitudinal distribution, and representativeness in the country's natural regions. Morphological characters that facilitate differentiation of the genera present in the country are described with information on diagnostic characters, geographic distribution, and a preliminary estimate of the number of species for each genus. A key to separate the genera in Colombia is also given.
\end{abstract}

Key words: Calyptranthes, Colombia, Eugenia, flora of Colombia, Myrcia, Myrtaceae.

\section{Introducción}

En la flora nativa colombiana la familia Myrtaceae es reconocida por su presencia en todas las formaciones vegetales y en todo el gradiente altitudinal del país. Con base en estimativos del posible número de angiospermas en Colombia (23.089 especies; Bernal, et al., 2007), y teniendo en cuenta que en nuestro país existen entre 160 y 180 especies de Myrtaceae (datos preliminares), la familia representa entre el 0,7 y el 0,8\% de las plantas angiospermas en el territorio nacional. A pesar de este bajo porcentaje, en áreas como la Amazonia colombiana, específicamente en el Parque Nacional Natural Amacayacu, las mirtáceas se encuentran entre las 15 familias de plantas vasculares más diversas (Rudas \& Prieto, 2005). Igualmente, en las franjas de páramo de los macizos de Chingaza y Sumapaz, las mirtáceas están entre las 15 familias con mayor número de especies y de géneros (Rangel-Ch., 2000). En diversos estudios taxonómicos de Myrtaceae en Colombia llevados a cabo en los últimos quince años se han encontrado interesantes endemismos en especies de Calyptranthes Sw., Myrcia DC. ex Guill. y Myrcianthes O. Berg (Parra-O., 2001, 2002, 2004a, 2012), y se ha registrado el redescubrimiento de un género nativo recolectado en el país una sola vez hace más de 140 años (Parra-O., 2003).

Los trabajos taxonómicos en Myrtaceae de Colombia son escasos y se han orientado a describir nuevas especies (Parra-O., 2001, 2002, 2004a, 2011a, 2012, 2013), a elaborar listados regionales (Parra-O., 2004b, 2011b) y a documentar nuevos registros o registros corológicos interesantes (Parra-O., 2003, 2004c). Desde el punto de vista taxonómico, la mayor dificultad para estudiar las mirtáceas es que en la mayoría de las ocasiones debe contarse con flores o frutos para poder determinar los especímenes a nivel de género. Además, algunos de los caracteres clave para delimitar

\section{Correspondencia:}

Carlos Parra-O., caparrao@unal.edu.co

Recibido: 6 de febrero de 2014

Aceptado: 1 de mayo de 2014 
géneros de Myrtaceae, especialmente los relacionados con la morfología del embrión, son de difícil interpretación y pocas veces se explican en los tratamientos taxonómicos de las floras locales. Si bien existen tratamientos taxonómicos y otras publicaciones que permiten identificar los géneros de Myrtaceae presentes en Colombia (Landrum \& Kawasaki, 1997; McVaugh, 1956, 1958, 1963, 1968), varios de estos trabajos fueron elaborados para Myrtaceae de otros países e incluyen taxones de la familia que no están en nuestro país. Por ejemplo, el excelente trabajo de Landrum \& Kawasaki (1997), que estudia la composición genérica de Myrtaceae en el Brasil, incluye entre los géneros de ese país a siete que no crecen naturalmente ni en forma cultivada en Colombia.

En el momento no se dispone del tratamiento taxonómico de Myrtaceae ni de ninguno de los géneros de la familia que crecen en Colombia. El objetivo de este trabajo es presentar una sinopsis de los géneros de Myrtaceae nativos e introducidos en el país, precisando los caracteres morfológicos que permiten diferenciarlos entre sí. Se incluye, igualmente, una clave genérica y una estimación preliminar del número de especies de cada uno de los géneros de Myrtaceae presentes en el país.

\section{Consideraciones generales sobre la familia Myrtaceae en Colombia}

En Colombia existen 24 géneros y 165 especies de la familia Myrtaceae. De estos, nueve géneros (Acca O. Berg, Corymbia K. D. Hill \& L.A. S. Johnson, Eucalyptus L’Hér., Leptospermum J. R. Forst. \& G. Forst, Melaleuca L., Metrosideros Banks ex Gaertn., Myrtus L., Pimenta Lindl., Syzygium P. Browne ex Gaertn.) y 26 especies son introducidos. Las especies nativas de Myrtaceae pertenecen a 15 géneros (Calycolpus O. Berg, Calycorectes O. Berg, Calyptranthes, Campomanesia Ruiz \& Pav., Eugenia L., Marlierea Cambess., Myrcia, Myrcianthes, Myrciaria O. Berg, Myrrhinium Schott, Myrteola O. Berg, Plinia L., Pseudanamomis Kausel, Psidium L., Ugni Turcz.) y comprenden en total 139 especies, de las cuales solo catorce son endémicas; seis de estas especies endémicas pertenecen a Calyptranthes, lo que corresponde a un $26 \%$ de las especies del género presentes en el país. El género de Myrtaceae con el mayor número de especies endémicas del país es Calyptranthes (seis especies), aunque este número puede estar sobreestimado debido a la falta de estudios taxonómicos más detallados en géneros como Eugenia y Myrcia; la mayor parte de las publicaciones taxonómicas en Myrtaceae colombianas se ha enfocado en Calyptranthes (Parra-O., 2001, 2002, 2004a, 2004c). Myrcia y Eugenia son los géneros con mayor número de especies endémicas, con cuatro, seguido de Calyptranthes, con tres.

Eugenia es el género más diverso entre las Myrtaceae colombianas, con 42 especies, seguido de Myrcia, con 27 especies, y de Calyptranthes, con 23 especies. La familia tiene una amplia distribución altitudinal en el territorio nacional, con excepción de Marlierea y Pseudanamomis (especies restringidas a altitudes por debajo de los 1.000 m), y Myrteola y Ugni (especies restringidas a altitudes por encima de los $2.200 \mathrm{~m}$ ). El $52 \%$ de las especies nativas de Myrtaceae en Colombia se distribuye exclusivamente entre los 0 y los 1.000 metros y tan sólo cerca del $10 \%$ es exclusivo de altitudes entre los 2.000 y 3.500 metros. La mayoría de las mirtáceas nativas del país crecen en las zonas de vida tropical y subandina, aunque existen géneros casi exclusivos (e.g., Myrcianthes) o exclusivos (e.g., Myrteola, Ugni) de las franjas andinas y del límite con el páramo.

En las regiones naturales de Colombia, las mirtáceas nativas están mejor representadas en la Amazonia (65 especies), seguida por la región Andina (43 especies) y por la Orinoquia (24 especies). Las regiones de la Amazonia y la Pacífica son las más interesantes en Colombia para el estudio de las mirtáceas nativas, debido al elevado número de especies de la familia en la primera de dichas regiones y al mayor número de endemismos en la segunda. Se estima que dentro de géneros como Eugenia y Myrcia existen al menos 0,5 veces más especies nativas sin describir, en comparación con el número de especies reconocidas para el país. Posiblemente, el número total de plantas Myrtaceae nativas del país se incrementará a unas 180 especies cuando se complete la revisión taxonómica de géneros como Eugenia y Myrcia.

Hoy se estima que hay un gran riesgo de que varias especies de Eucalyptus introducidas en nuestro país (e.g., Eucalyptus camaldulensis Dehnh., Eucalyptus globulus Labill.) se conviertan en invasoras (Baptiste, M., et al., 2010), o que ya lo sean en ecosistemas naturales como los humedales de la Sabana de Bogotá, debido a sus diversos y exitosos tipos de reproducción, y a que compiten ventajosamente con las especies nativas por recursos como los nutrientes, el agua y la luz (Díaz-Espinosa, et al., 2012).

\section{Caracteres morfológicos de las especies de Myrtaceae colombianas a nivel de familia}

Las especies de Myrtaceae nativas de Colombia son fáciles de reconocer vegetativamente porque poseen hojas simples, opuestas y con glándulas translúcidas inmersas en la lámina foliar; cuando se estruja la lámina foliar, las glándulas se rompen y liberan compuestos fragantes. Además, la lámina foliar casi siempre presenta un nervio marginal al cual se unen los nervios secundarios e intersecundarios. La combinación de todos estos caracteres es prácticamente exclusiva de nuestras especies nativas de Myrtaceae, las cuales no poseen estípulas ni cicatrices interpeciolares como se observa en otras familias de plantas nativas colombianas con hojas simples y opuestas.

Landrum \& Kawasaki (1997) analizaron las familias de angiospermas que pueden confundirse con Myrtaceae y los 
caracteres que permiten diferenciar a esas familias de las de Myrtaceae nativas de Brasil. Algunos géneros o especies de estas familias (Clusiaceae, Hippocrateaceae, Loranthaceae, Lythraceae, Malpighiaceae, Melastomataceae, Monimiaceae, Rubiaceae, Rutaceae y Vochysiaceae), también podrían confundirse en nuestro país con especies de la familia Myrtaceae. En los herbarios colombianos es común que se encuentren mal determinados, como supuestas Myrtaceae, especímenes de Mouriri (Melastomataceae) y de Alzatea verticillata Ruiz \& Pav. (Alzateaceae). Mouriri y Alzatea, aunque presentan hojas opuestas, no poseen glándulas translúcidas, que sí son propias de Myrtaceae. En cuanto a los caracteres reproductivos, Mouriri se diferencia claramente de las mirtáceas por presentar pocos estambres con dehiscencia poricida y frutos con canales verticales en la superficie interna de los restos del tubo del hipanto (Landrum \& Kawasaki, 1997). A su vez, Alzatea siempre presenta hojas coriáceas y subsésiles, inflorescencias en panículas, flores con cinco a seis lóbulos del cáliz, corola ausente, cinco estambres alternos a los lóbulos de la corola, ovario súpero y frutos en cápsulas loculicidas (Graham, 2004); ninguna de las mirtáceas nativas presenta solo cinco estambres, ovario súpero ni frutos en cápsulas.

Si bien los caracteres vegetativos son útiles para reconocer con precisión una mirtácea a nivel de familia, estos mismos caracteres son prácticamente inservibles para determinar el mismo espécimen a nivel de género. Los caracteres vegetativos de los géneros de Myrtaceae son convergentes y, en algunos casos, se encuentran asociados a adaptaciones particulares al hábitat. Un notorio ejemplo de convergencia de ciertos caracteres vegetativos entre géneros colombianos de Myrtaceae se presenta en las especies de Myrcianthes y Calyptranthes lozanoi C. Parra-O. (Figura 1). En Colombia, la mayoría de especies de Myrcianthes se encuentra en la franja andina, por encima de los 2.000 metros, principalmente en el bosque andino y altoandino, así como en el subpáramo y el páramo. En estas especies de Myrcianthes es común observar el desarrollo de una corteza engrosada de color grisáceo o amarillento en las ramitas jóvenes, y de hojas con láminas foliares coriáceas con nerviación prominente, especialmente en el envés; en general, las hojas de estas especies tienen menor tamaño que las de las mirtáceas que crecen en tierras bajas. Todas estas características están presentes en Calyptranthes lozanoi var. lozanoi, que es endémica de la Sierra Nevada de Santa Marta y crece entre los 2.000 y los 3.000 metros (Parra-O., 2001). En la revisión taxonómica inédita de Myrcianthes (Grifo, 1992), unos especímenes fueron determinados y citados erróneamente como Myrcianthes leucoxyla (Ort.) McVaugh; esos mismos especímenes fueron designados posteriormente como el holotipo y paratipo de C. lozanoi (Parra-O., 2001).

Con relación a las especies de la familia introducidas en nuestro país, estas presentan hojas simples, con glándulas translúcidas inmersas en la lámina foliar, alternas (Corymbia, Eucalyptus, Leptospermum, Melaleuca) u opuestas (Acca, Eucalyptus, Metrosideros, Myrtus, Pimenta y Syzygium).
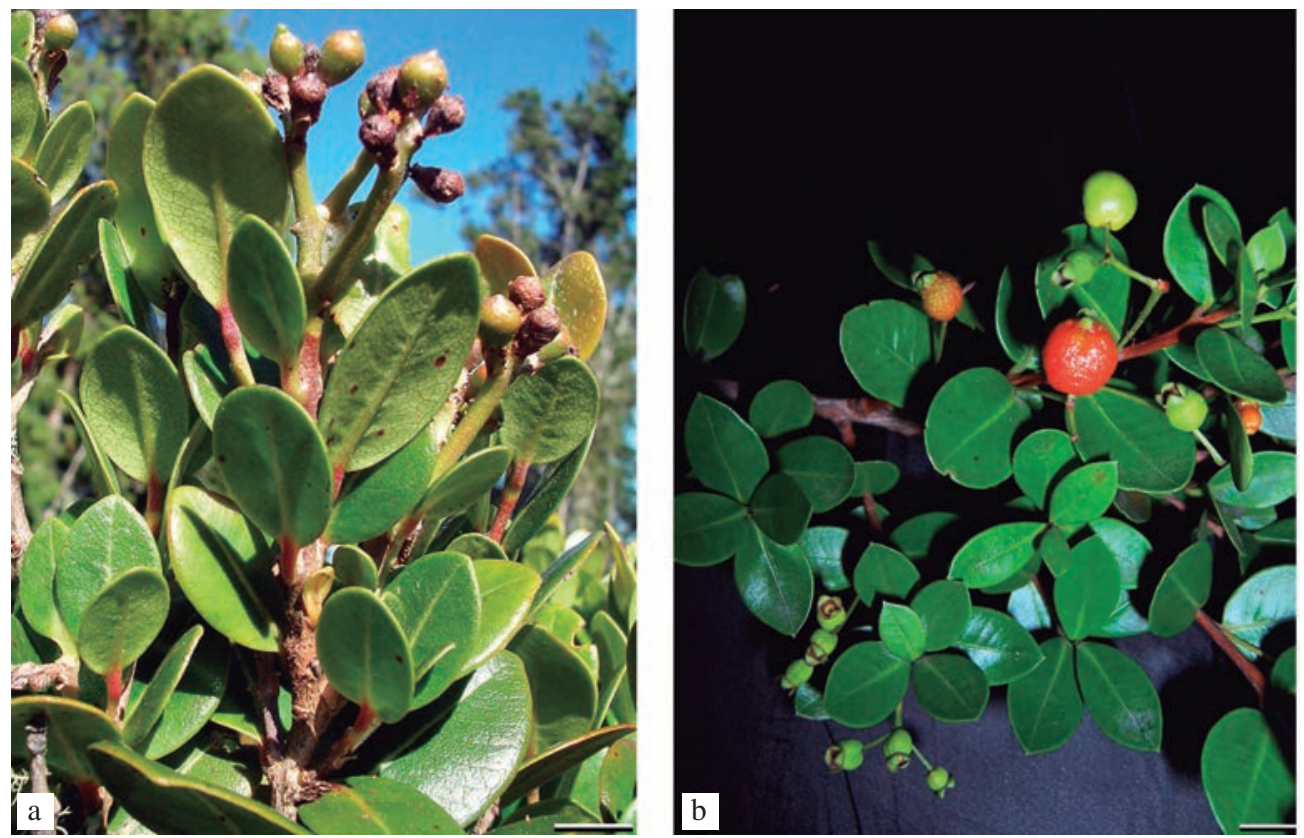

Figura 1. Convergencia de caracteres vegetativos entre géneros de Myrtaceae colombianos. a) Calyptranthes lozanoi C. Parra-O. subsp. lozanoi. (Parra-O. 784, COL); b) Myrcianthes leucoxyla (Ort.) McVaugh (Parra-O. 777, COL). Escala $=1 \mathrm{~cm}$. 
Es de anotar que la mayoría de especies de Eucalyptus presentan hojas alternas en estado adulto, mientras que en estado juvenil, o en los retoños, las hojas son opuestas, observándose en ocasiones hojas alternas y opuestas en un mismo individuo.

\section{Clasificaciones taxonómicas supragenéricas en Myrtaceae neotropicales nativas con frutos en baya}

En las clasificaciones taxonómicas clásicas (Berg, 18551856, 1857-1859) las subtribus y los géneros dentro de las mirtáceas neotropicales con frutos en baya se delimitaron con base en caracteres reproductivos, tales como el tipo de cáliz (y su apertura durante la antesis), el número de sépalos, el tipo de inflorescencia, el número de óvulos y, uno de los más importantes para Berg, la relación y el tamaño de los cotiledones, el hipocótilo y la radícula en el embrión. Este último conjunto de caracteres del embrión fue empleado por Berg para delimitar tres subtribus en la tribu Myrteae DC. (Myrciinae, Myrtinae y Eugeniinae), dentro de las cuales se clasificaron todos los géneros nativos de mirtáceas neotropicales con frutos en baya. A pesar de seguir esta división de subtribus para el tratamiento de Myrtaceae de la flora del Perú (McVaugh, 1958), posteriormente el mismo McVaugh (1968) consideró que tales subtribus eran grupos artificiales. Más que proponer nuevas categorías taxonómicas supragenéricas, McVaugh (1968) delimitó seis grupos (a los que no asignó ningún rango taxonómico), que representaban “líneas de especialización” en la evolución de los géneros de Myrtaceae de frutos con baya en el continente americano. A pesar de las críticas de McVaugh (1968) a las subtribus de Berg, estas siguieron empleándose en diferentes sinopsis y tratamientos taxonómicos (e.g., Landrum, 1986; Landrum \& Kawasaki, 1997), inclusive por el mismo McVaugh (McVaugh, 1969). Así mismo, en la delimitación de la mayoría de nuevos géneros de Myrtaceae suramericanos (Landrum, 1990, 1991; Salywon \& Landrum, 2007), las referencias a las subtribus de Berg son inevitables y tales géneros fueron asignados a una de sus tres subtribus. Sin embargo, Snow, et al., (2003) decidieron abandonar la clasificación de las tres subtribus por considerarla arquetípica y producto del pensamiento tipológico en la taxonomía de la familia. Wilson, et al., (2005) reconocieron a la tribu Myrteae como un grupo monofilético, pero no a las subtribus de Berg. Además, en un género de Myrtaceae recientemente descrito en Brasil (Algrizea Proença \& NicLugh.; Proença, et al., 2006), se observó que el embrión posee características exclusivas que no permiten que sea ubicado en ninguna las tres subtribus de Berg. Por otra parte, con base en estudios filogenéticos de los caracteres moleculares, Lucas, et al., (2007) concluyeron que las subtribus delimitadas por Berg no son monofiléticas. Basados en un análisis filogenético y en el estudio de caracteres morfológicos, estos autores propusieron siete subtribus informales dentro de la tribu
Myrteae; seis de estas subtribus informales contienen la mayoría de los géneros de Myrtaceae con frutos en baya que crecen espontáneamente en Suramérica.

\section{Caracteres morfológicos importantes para el reconocimiento de los géneros de Myrtaceae en Colombia}

A continuación se hace un análisis de los caracteres relevantes para delimitar los géneros en las Myrtaceae colombianas. Es necesario anotar que los géneros se caracterizan por un conjunto de caracteres, y ninguno de ellos, por sí solo, sirve para diferenciar un género de los otros. Además, los estados de los caracteres aquí mencionados como propios de un género, solo hacen referencia a la variación encontrada dentro de las especies de los géneros que crecen en Colombia. Por ejemplo, la única especie de Campomanesia que crece en Colombia tiene el cáliz con sépalos libres en el botón floral (ver la sinopsis del género abajo), pero existen especies de este género que presentan sépalos fusionados en el botón antes de la antesis (Landrum, 1986), y que no crecen de forma espontánea ni son cultivadas en nuestro país.

\section{Inflorescencia}

Las mirtáceas que crecen en Colombia poseen desde flores solitarias hasta inflorescencias muy ramificadas. En las inflorescencias básicas de las especies nativas de Myrtaceae colombianas existen dicasios (simples o compuestos; Figuras 2a, 2b), racimos propiamente dichos (Figura 2c), fascículos (Figura 2d), glomérulos (Figura 2e) y panículas (Figura 2f).

De acuerdo con McVaugh (1956) y Landrum \& Kawasaki (1997), en Myrtaceae existen modificaciones de las inflorescencias en racimo con relación al desarrollo del eje central. Aunque el eje central existe en algunas inflorescencias racemosas, este se acorta notoriamente y puede ser más corto incluso que los pedicelos florales; en estos casos se puede definir la inflorescencia como cortamente racemosa. En algunos casos, el eje central del racimo es muy corto y se observan tan solo dos flores que parecen estar una al lado de la otra, como en algunas especies de Calycolpus. En los casos más extremos, el eje central del racimo se reduce tanto que las flores ya no comparten un eje en común, sino que se originan de un mismo punto en una ramita, y la inflorescencia se denomina fascículo (cuando las flores son pediceladas; Figura 2d) o glomérulo (cuando las flores son sésiles, Figura 2e).

En las mirtáceas nativas colombianas existen variaciones importantes entre las inflorescencias descritas arriba. Por ejemplo, algunos géneros nativos como Myrrhinium poseen inflorescencias particulares descritas como dicasios simples agregados en racimos cortos (Parra-O., 2003; véase su figura 1), que se desarrollan en ejes de ramas maduras desprovistos de hojas, aparentando ser caulinares (Weberling, 1988). En algunas especies de Myrcianthes colombianas (e.g., M. karsteniana (Berg) McVaugh) los dicasios compuestos 

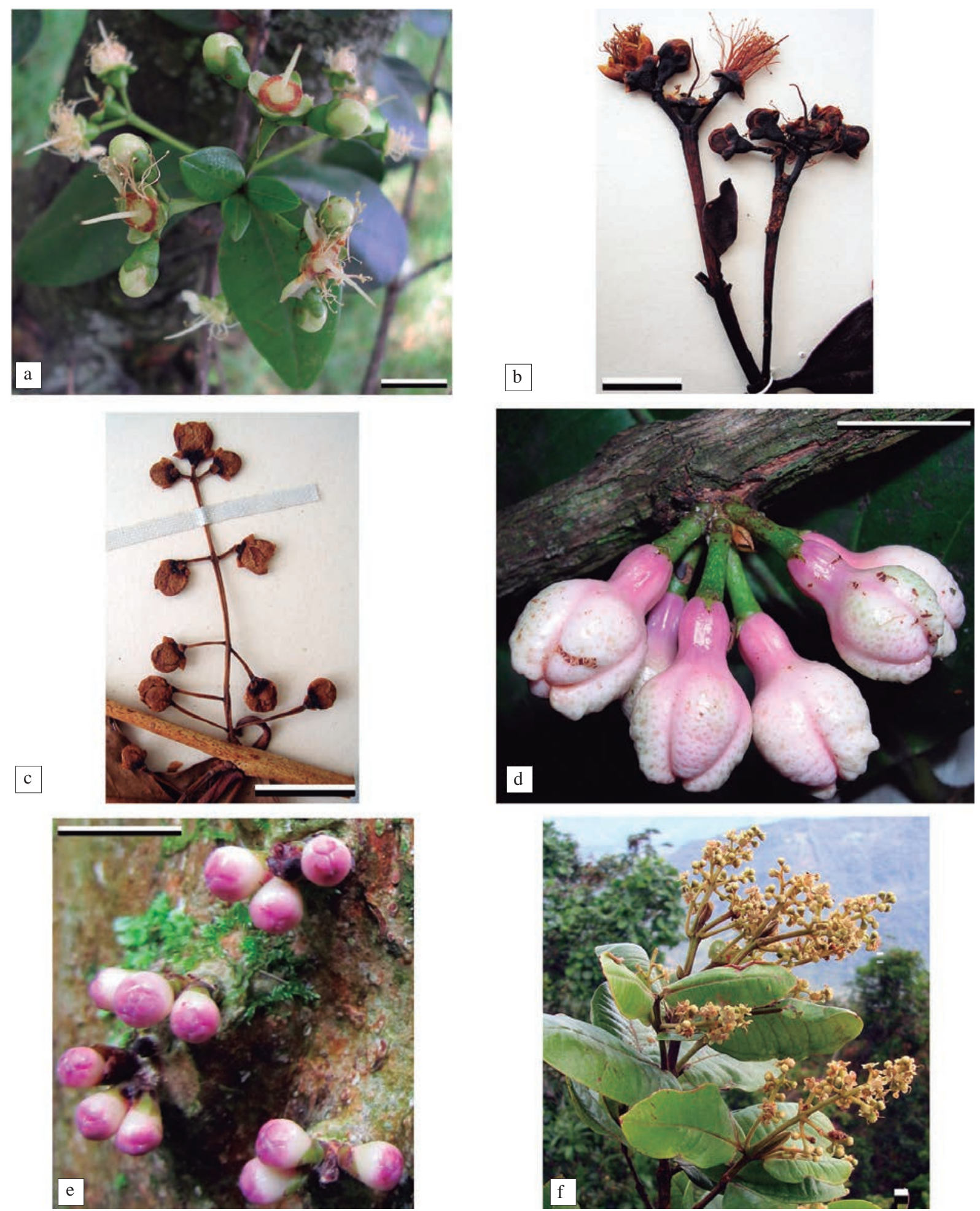

Figura 2. Inflorescencias básicas de las especies nativas de Myrtaceae colombianas. a) Dicasios simples (Myrcianthes sp., Parra-O. 794, COL); b). Dicasios compuestos [Myrcianthes rhopaloides (Kunth) McVaugh, González et al. 1684, COL]; c) Racimos propiamente dichos (Eugenia florida DC., Uribe 1045, COL); d) Fascículos (Eugenia sp., Parra-O. 720, COL); e) Glomérulos (Plinia sp., Raz 1309, COL. Foto L. Raz); f) Panículas (Myrcia sp., Parra-O. 781, COL). Escala = $1 \mathrm{~cm}$ 
forman nuevos ejes florales (ramas accesorias sensu Weberling, 1988) en las ramificaciones de segundo orden y lucen como panículas irregulares (=dicasios irregularmente ramificados sensu Grifo, 1992). En Pseudanamomis se observa frecuentemente que la inflorescencia básica, un dicasio simple, puede desarrollar flores adicionales que la hacen ver como una umbela; en estos casos, generalmente ambos tipos de inflorescencia (dicasios e inflorescencias umbeloides) están presentes en un mismo individuo.

En los géneros y las especies nativas colombianas de Myrtaceae, las flores solitarias se presentan en algunas especies de Calycolpus, Campomanesia, Eugenia, Myrcianthes y Psidium, y de forma exclusiva en Myrteola y Ugni. Los dicasios son comunes en la mayoría de las especies de Myrcianthes, en Pseudanamomis (presentado también inflorescencias umbeloides, ver párrafo anterior), y en algunas especies de Psidium. Los racimos propiamente dichos se encuentran en Campomanesia y en algunas especies de Eugenia y Psidium; el racimo con un eje supremamente corto que porta solo dos flores es característico de Calycolpus. Los glomérulos son evidentes en Plinia y en algunas especies de Myrciaria; los fascículos se encuentran en Calycorectes y en algunas especies de Eugenia y de Myrciaria. Calyptranthes, Marlierea y Myrcia generalmente presentan panículas bien desarrolladas, en tanto que Myrrhinium posee inflorescencias en dicasios simples que se agregan en racimos cortos.

En los géneros y las especies de Myrtaceae introducidas en Colombia, Leptospermum y Myrtus poseen flores solitarias, Melaleuca presenta inflorescencias en espigas, Syzygium desarrolla racimos y panículas, y Pimenta posee panículas. Corymbia y Eucalyptus presentan inflorescencias particulares en las que la unidad básica de la inflorescencia es una umbela con cinco a siete flores (algunas veces la umbela es irregular), y varias de estas umbelas pueden disponerse en racimos o panículas de diferente longitud. Metrosideros tiene una inflorescencia compleja, definida como una inflorescencia compuesta que posee un eje principal a su vez ramificado en varios ejes secundarios, en los cuales los ejes secundarios terminan en cimas con tres flores (Schmidt-Adam \& Gould, 2000). Acca presenta variación en la disposición de sus flores, pues puede presentar flores solitarias, inflorescencias en racimos muy cortos con solo dos flores o dicasios con tres flores y el eje principal muy corto.

\section{Cáliz}

En las Myrtaceae colombianas, las características del cáliz son muy importantes para diferenciar géneros nativos entre sí. El primer carácter que debe analizarse es el tipo de cáliz, para verificar si los sépalos se encuentran fusionados unos con otros en el botón floral (Figura 3a); si es así, este primer estado de carácter se denomina cáliz cerrado. En el segundo estado de carácter los sépalos son libres (Figura 3b) y se denomina cáliz abierto. En caso de poseer cáliz cerrado, la fusión de los sépalos puede ser incompleta, casi completa o completa. Cuando existe la fusión completa de los sépalos es frecuente que así soldados formen una estructura en forma de capuchón (denominada caliptra) en la porción apical del botón floral; en estos casos, el botón floral se define como botón floral caliptrado. Esta caliptra puede presentar o no un apículo en su ápice; cuando este se presenta puede extenderse hasta un tercio de la longitud total del botón floral. El botón caliptrado presenta dos tipos de dehiscencia en la antesis; en el primero, la caliptra se desprende claramente como una unidad (Figura 3c), que puede caer durante la antesis o permanecer adherida al hipanto a lo largo de todo el desarrollo de la flor. El primer tipo de dehiscencia, típico de géneros de Myrtaceae nativos de Colombia como Calyptranthes, conduce a la formación de una cicatriz anular en la parte superior del fruto que la mayoría de las veces es fácil de distinguir (Figura 3d). Sin embargo, el fruto de Myrciaria O. Berg presenta una cicatriz similar, que no corresponde a la dehiscencia del cáliz durante la antesis sino a la de todo el hipanto (Landrum \& Kawasaki, 1997). El género introducido Corymbia (con frutos capsulares) también presenta el cáliz fusionado en forma de caliptra. En el segundo tipo de dehiscencia del botón caliptrado, el cáliz fusionado no se desprende como una sola unidad sino que se rasga longitudinalmente en lóbulos irregulares o relativamente regulares (Figura 3e). Este tipo de dehiscencia es propia de géneros como Marlierea y, de hecho, es el único carácter que diferencia a este género de Calyptranthes. Algunas especies de Psidium que crecen en Colombia (e.g., P. friedrichsthalianum (O. Berg) Nied.), también presentan este tipo de dehiscencia. En géneros como Calycorectes y Plinia el cáliz está fusionado o parcialmente fusionado, y en el segundo, el cáliz también se rasga en lóbulos irregulares.

Aunque la presencia del cáliz cerrado en el botón floral parece ser convergente a nivel genérico y su uso ha sido criticado para delimitar géneros dentro de Myrtaceae (Landrum, 1984), en la práctica este carácter, conjuntamente con otros, permite la identificación de géneros como Calyptranthes y Marlierea. Cuando los especímenes carecen de flores y solo poseen frutos, con frecuencia se puede observar en su parte apical remanentes de los sépalos, los lóbulos, la caliptra, o cicatrices que permiten deducir el tipo de cáliz que la flor poseía.

Entre los géneros y las especies nativas colombianas de Myrtaceae, Calycolpus, Campomanesia, Eugenia, Myrcia, Myrcianthes, Myrciaria, Myrrhinium, Myrteola, Pseudanamomis, y algunas especies de Psidium y Ugni se caracterizan por tener sépalos libres. Los sépalos libres son exclusivamente cuatro (Eugenia, Myrciaria y Myrrhinium) o exclusivamente cinco (Calycolpus, Campomanesia y Psidium). En la mayoría de especies de Myrcia hay cinco 

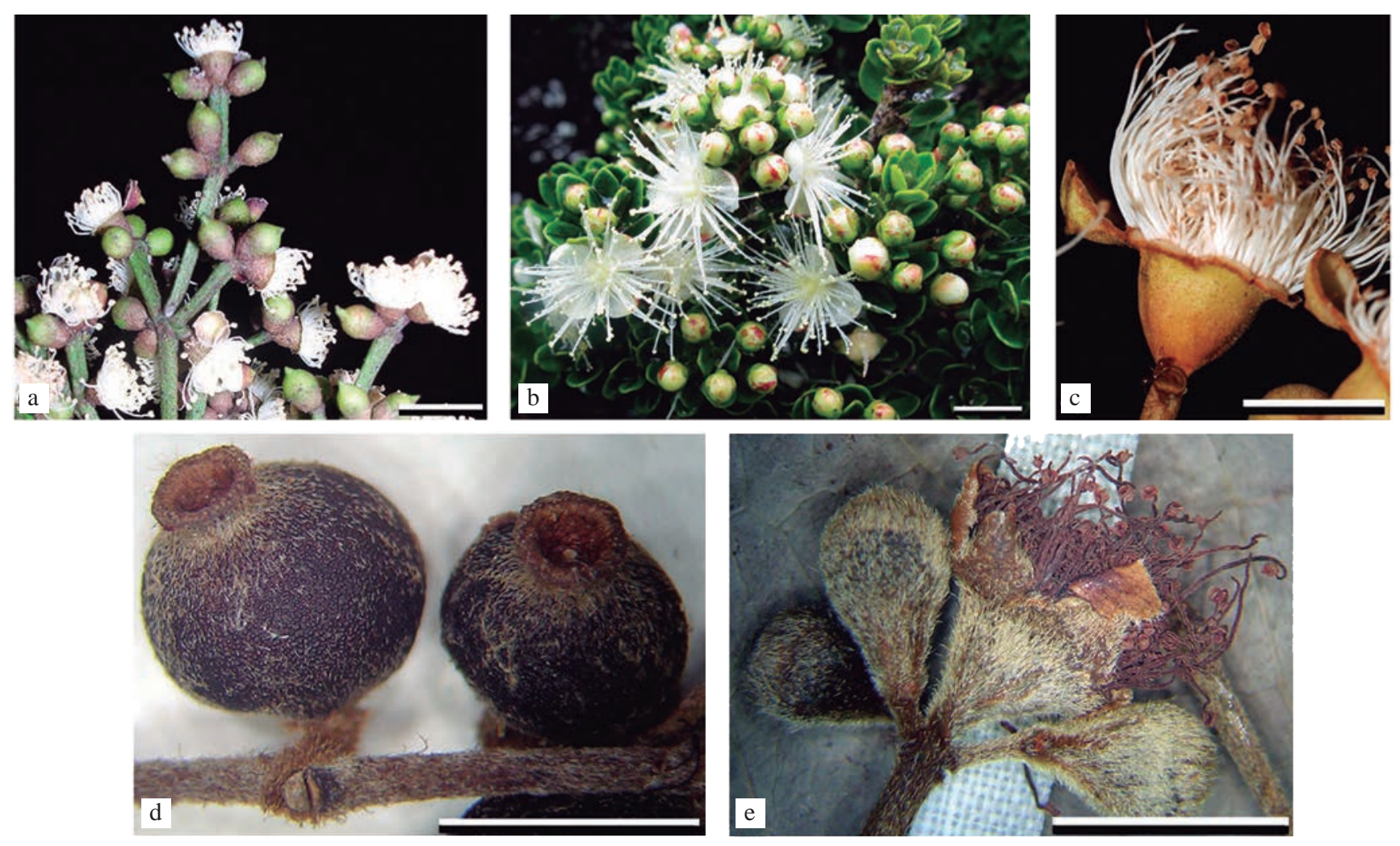

Figura 3. Características del cáliz en los géneros de Myrtaceae que crecen en Colombia. a) Cáliz cerrado, con los sépalos fusionados en los botones florales (Calyptranthes sp., Parra-O. 789, COL); b). Cáliz abierto, con los sépalos claramente diferenciados en los botones florales [Myrcianthes myrsinoides (Kunth) Grifo, Rodríguez-C. 2206, COL. Foto B. V. Rodríguez]; c) Antesis en la que el cáliz cerrado se desprende como una unidad en forma de caliptra (Calyptranthes maxima McVaugh, González \& Isaza 699, COL. Foto M. F. González); d) Cicatriz anular en la parte superior del fruto producto del desprendimiento de la caliptra después de la antesis [Calyptranthes chytraculia (L.) Sw. var. americana McVaugh, Moreno 546, COL]; e) Antesis en la que el cáliz cerrado se desprende rasgándose longitudinalmente en lóbulos irregulares (Marlierera spruceana O. Berg, Prance et al. 2686, COL). Escala $=0.5 \mathrm{~cm}$.

sépalos (algunas especies presentes en Colombia tienen sólo cuatro), mientras que en la mayoría de especies de Myrcianthes se presentan cuatro sépalos (una sola especie de este género en Colombia tiene individuos con cuatro, o con cinco sépalos). En ocasiones se presentan cuatro o cinco sépalos incluso en flores diferentes de un mismo individuo [Myrteola (generalmente cuatro, algunas veces cinco), Pseudanamomis (cuatro o cinco) y Ugni (generalmente cinco, algunas veces, cuatro)]. Por el contrario, Calycorectes O. Berg, Calyptranthes, Marlierea, Plinia y algunas especies de Psidium poseen botones con los sépalos fusionados, en los cuales la fusión es incompleta o casi completa (Calycorectes y Plinia), o totalmente completa con la formación de caliptra (Calyptranthes, Marlierea y algunas especies de Psidium). La caliptra en Calyptranthes se desprende como una sola unidad, mientras que en Marlierea y en algunas especies de Psidium se rasga en lóbulos irregulares o más o menos regulares. En cuanto a los géneros introducidos, Corymbia y Eucalyptus poseen cálices cerrados con caliptra; Acca,
Leptospermum, Melaleuca, Metrosideros, Myrtus, Pimenta y Syzygium presentan sépalos libres, con cuatro sépalos (Acca y Syzygium), con cinco (Leptospermum, Melaleuca, Metrosideros y Myrtus) o entre cuatro o cinco (Pimenta).

\section{Fruto y embrión}

Con relación a los frutos de las mirtáceas nativas colombianas, todos los géneros de Myrtaceae nativos del continente americano presentan frutos en baya, con excepción de Tepualia Griseb. (género monoespecífico nativo de Argentina y Chile).

De los géneros de Myrtaceae introducidos en nuestro país, cuatro presentan frutos en baya (Acca, Myrtus, Pimenta y Syzygium), mientras que cinco poseen frutos capsulares (Corymbia, Eucalyptus, Leptospermum, Melaleuca y Metrosideros).

Con relación al embrión, y como se mencionó anteriormente (véase el apartado "Clasificaciones taxonómicas supragenéricas en las Myrtaceae nativas neotropicales con frutos en baya"), un 
conjunto de caracteres del embrión se utilizó como base de la delimitación de tres subtribus en la tribu Myrteae, subtribus que actualmente no se consideran como grupos monofiléticos. Para analizar los caracteres del embrión es necesario abrir el fruto, extraer la semilla y retirar cuidadosamente la testa; en el embrión es necesario identificar los cotiledones, el hipocótilo y la radícula, así como su tamaño y su relación.

En algunos embriones se pueden observar los cotiledones libres, foliáceos, contortuplicados, más anchos que el hipocótilo y rodeados por él; en estos casos, el hipocótilo y los cotiledones tienen aproximadamente la misma longitud (McVaugh, 1958; Landrum \& Kawasaki, 1997; Figura 4a). Este tipo de embrión, denominado mircioide, definía a la subtribu Myrciinae de Berg (1855-1856, 1857-1859). En los

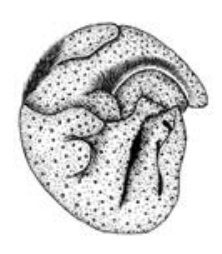

$\mathrm{a}$
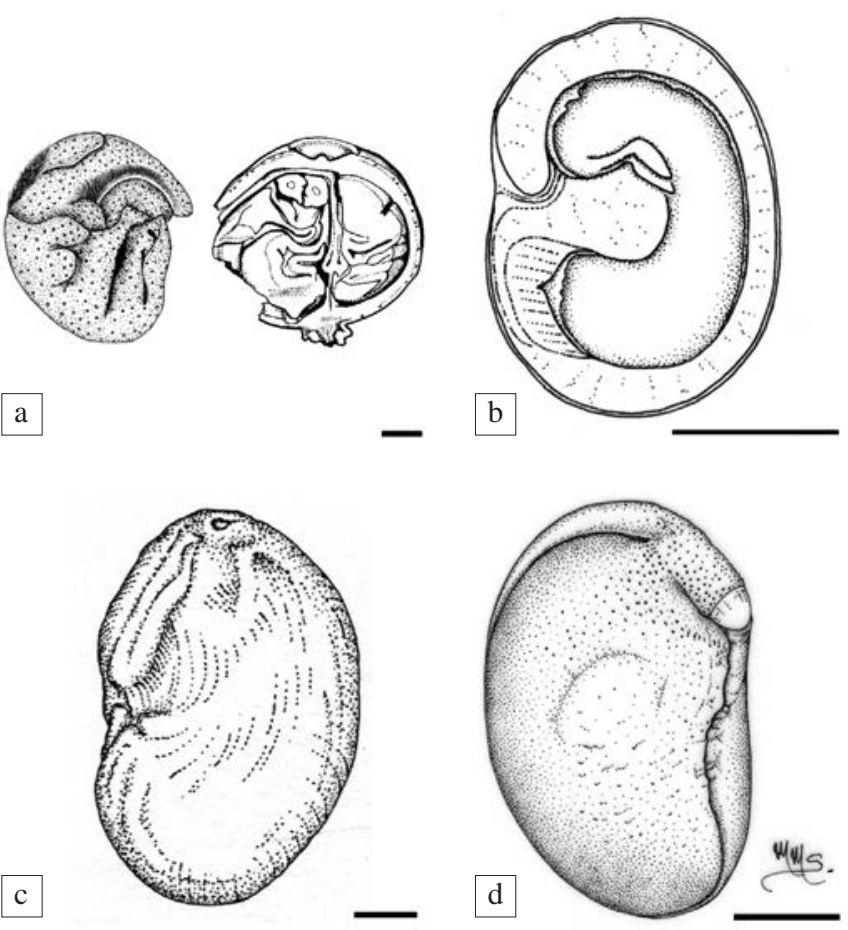

Figura 4. Tipo de embrión en las semillas de los géneros nativos de Myrtaceae colombianas. a) A la izquierda, semilla sin testa, en la que se observa el embrión mircioide; a la derecha, corte transversal del fruto en el que se observa el interior de dos semillas con los cotiledones contortuplicados, propios del embrión mircioide (Calyptranthes buchenavioides C. Parra-O., Parra-O., 2004a; Calyptranthes lozanoi C. Parra-O. var. lozanoi, Parra-O. 2001); b) Corte transversal de la semilla que muestra el embrión mirtoide con los cotiledones y el hipocótilo (Psidium laruotteanum Cambess., Parra-O. \& Rodríguez 762, COL); c) Semilla sin testa en la que se observa el embrión eugenioide con los cotiledones totalmente fusionados (Eugenia fernandez-alonsoi C. Parra-O.; Parra-O., 2011a); d) Semilla sin testa en la que se observa el embrión eugenioide con los cotiledones separados y el hipocótilo evidente (Myrcianthes sp., Parra-O. 805, COL). Escala = $2 \mathrm{~mm}$ géneros de Myrtaceae nativos de Colombia, dicho embrión es característico de algunos como Calyptranthes, Marlierea y Myrcia. Otros embriones presentan, por el contrario, los cotiledones angostos y de la misma longitud o mucho menores que el hipocótilo y, a veces, en forma de 'C' (McVaugh, 1958; Landrum \& Kawasaki, 1997; fig. 4b); este embrión, llamado mirtoide, definía a la subtribu Myrtinae de Berg (1855-1856, 1857-1859), y es característico de los géneros nativos Calycolpus, Campomanesia, Myrrhinium, Myrteola, Psidium y Ugni, y de los géneros introducidos Acca, Myrtus y Pimenta.

El otro tipo de embrión que se observa en las mirtáceas colombianas es el denominado embrión eugenioide, que definía a la subtribu Eugeniinae de Berg (1855-1856, 1857-1859), y se caracteriza por un corto hipocótilo y unos cotiledones grandes plano-convexos que pueden estar separados o, por el contrario, estar parcial o completamente fusionados en una sola masa indistinguible del hipocótilo (McVaugh, 1958; Landrum \& Kawasaki, 1997; Figura 4c, d). Este tipo de embrión se presenta en los géneros nativos Calycorectes, Eugenia, Myrcianthes, Myrciaria, Plinia y Pseudanamomis, y en el género introducido Syzygium.

Para los demás géneros de Myrtaceae introducidos en Colombia (Corymbia, Eucalyptus, Leptospermum, Melaleuca y Metrosideros), los caracteres del embrión no se han usado de forma individual para caracterizar grupos supragenéricos que los incluyan, pero sí han tenido alguna relevancia para definir secciones, por ejemplo, dentro de Eucalyptus (Chippendale, 1988).

\section{Genéros de Myrtaceae introducidos en Colombia}

Las mirtáceas introducidas en Colombia pertenecen a nueve géneros, cinco de los cuales (Corymbia, Eucalyptus, Leptospermum, Melaleuca y Metrosideros) presentan frutos capsulares; los otros cuatro (Acca, Myrtus, Pimenta y Syzygium) poseen frutos en baya. La mayoría de estos géneros provienen de Australia, aunque también hay géneros de Europa, Asia, el Caribe y Suramérica.

\section{Acca O. Berg}

Género compuesto por tres especies nativas del Perú y del área comprendida entre el sureste brasileño y Uruguay (Landrum, 1986). En Colombia está representado solamente por Acca sellowiana (Berg) Burret, especie introducida y cultivada como planta frutal (feijoa) u ornamental. Acca no debe considerarse como un género naturalizado en Colombia, ya que su única especie no crece de forma espontánea y siempre está asociada a cultivos, granjas o áreas de ornato controladas por la mano del hombre. A. sellowiana se caracteriza por tener hojas opuestas con el envés grisáceo, flores solitarias, inflorescencias en racimos muy cortos con solo dos flores, o dicasios de eje principal muy corto con tres flores, pétalos 
carnosos con margen fuertemente involuta de color rosado a púrpura por la haz, filamentos de los estambres de color rojo, frutos en baya con mesocarpio blancuzco y numerosas semillas con embrión mirtoide.

\section{Corymbia K.D. Hill \& L.A.S. Johnson}

Género de 113 especies que crecen principalmente en el norte de Australia, con algunas especies en Papua Nueva Guinea (Hill \& Johnson, 1995). Aunque solía considerársele parte de Eucalyptus, en estudios recientes se establece su monofilia y su estatus genérico (Parra-O., et al., 2006, 2009). En Colombia existen tres especies introducidas que han sido utilizadas como árboles ornamentales, entre las que se destaca Corymbia ficifolia (F. Muell.) K.D. Hill \& L.A.S. Johnson, por sus flores vistosas con numerosos estambres de color rosado a rojizo. Las especies que crecen en Colombia se distinguen por presentar un exudado rojizo al hacer un corte en el tronco, hojas adultas alternas, botones florales caliptrados, inflorescencias en umbelas dispuestas a su vez en racimos o en panículas, pétalos blancos o rojizos y frutos capsulares urceolados.

\section{Eucalyptus L'Her}

Este género está constituido por más de 600 especies, la mayoría de las cuales son nativas de Australia (Ladiges, et al., 2003). En Colombia se encuentran cerca de 10 especies introducidas que se usan como plantas ornamentales, medicinales o maderables (Pérez-Arbeláez, 1996). Las especies de este género cultivadas en Colombia se pueden reconocer por tener botones florales caliptrados, generalmente hojas adultas alternas (algunas opuestas), inflorescencias en umbelas y frutos capsulares globulares u ovoides.

\section{Leptospermum J. R. Forst. \& G. Forst}

Género de 79 especies que crecen en el sureste de Asia, Nueva Guinea, Australia y Nueva Zelanda (Thompson \& Logan, 1991). En Colombia se encuentra una especie introducida que se cultiva para uso ornamental; esta especie se caracteriza por tener hojas alternas, coriáceas y casi sésiles, flores solitarias con cinco sépalos libres, con pétalos blancos a rojizos, numerosos estambres más cortos que los pétalos y frutos capsulares.

\section{Melaleuca L.}

Este género posee cerca de 220 especies que crecen en Australia, Nueva Guinea y la región de Malasia (Wilson, 1991). En este artículo se sigue el criterio de Craven (2006) de que Callistemon R. Br. no tiene caracteres lo suficientemente estables para ser considerado como un género separado de Melaleuca, y que debe ser incluido en este. En Colombia se encuentran cinco especies introducidas que se cultivan como ornamentales, las cuales se reconocen por tener hojas alternas, inflorescencias en espiga con numerosas flores de largos estambres de color rojo (de ahí que algunas especies se conocen comúnmente como "escobillón rojo" o "árbol del cepillo”), y frutos capsulares.

\section{Metrosideros Banks ex Gaertn.}

Género con cerca de 50 especies que crecen principalmente en Nueva Zelanda, Nueva Caledonia, Hawai y Nueva Guinea, algunas pocas especies en islas distribuidas a lo largo del Pacífico y una sola en Suráfrica (Wright, et al., 2000; Mabberley, 2008). En Colombia se encuentra una especie introducida, la cual se cultiva como planta ornamental; se caracteriza por poseer hojas opuestas con el envés grisáceo, inflorescencia muy ramificada cuyos ejes secundarios terminan en cimas con tres flores, botones florales y sépalos con pubescencia grisáceo-verdosa, estambres de color rojo, estilos largos y frutos capsulares.

\section{Myrtus L.}

Género compuesto por dos especies que crecen naturalmente en la región mediterránea y en el norte de África (Mabberley, 2008). En Colombia se encuentra una especie introducida, utilizada como planta ornamental, que presenta hojas opuestas con el ápice agudo, flores solitarias con largos pedicelos y con cinco sépalos libres, con pétalos blancos, numerosos estambres tan largos como los pétalos y frutos en baya cuyas semillas presentan embrión de tipo mirtoide.

\section{Pimenta Lindl.}

Este género posee 15 especies que crecen de forma natural principalmente en el Caribe y Centroamérica, y una sola de ellas en el sureste de Brasil (Landrum, 1986). En Colombia existen dos especies, una de las cuales (P. dioica (L.) Merr.) se encuentra en las Islas de San Andrés, Providencia y Santa Catalina; es posible que $P$. dioica esté naturalizada en las Islas, aunque no existe evidencia sobre esto, por lo que en este trabajo se considera al género como introducido; $P$. racemosa (Mill.) J. W. Moore, la otra especie del género presente en Colombia, se cultiva en el territorio nacional continental. Estas especies se reconocen por sus hojas opuestas y aromáticas, inflorescencias en panículas, flores con cuatro o cinco sépalos libres, frutos en baya y semillas con embrión mirtoide.

\section{Syzygium Gaertn.}

Con más de 1.000 especies que crecen en África, Asia y Australia (Chantaranothai \& Parnell, 1994), Syzygium es uno de los géneros más diversos entre las mirtáceas. En Colombia está representado por cinco especies introducidas, las cuales se cultivan como árboles ornamentales o frutales ('pomarrosos'). Por las mismas consideraciones mencionadas con respecto a Acca (ver arriba), no se considera aquí a Syzygium como un género naturalizado en Colombia. Las especies de Syzygium que crecen en el país presentan hojas opuestas, inflorescencias en racimos cortos o panículas, 
pétalos de color blanco o rosado, filamentos de los estambres de color blanco o rosado, frutos rosados o púrpuras en la madurez, globosos, elipsoides o piriformes, y una sola semilla por fruto cuyo embrión es similar al eugenioide, pero con los cotiledones divididos.

\section{Géneros de Myrtaceae nativos de Colombia}

Las mirtáceas nativas de Colombia pertenecen a 15 géneros, ninguno de los cuales es endémico; todos ellos presentan frutos en baya. Algunas especies de Campomanesia, Eugenia, Myrciaria y Psidium se utilizan en nuestro país principalmente como recurso alimenticio (e.g., Romero-Castañeda, 1991; Pérez-Arbeláez, 1996; Lozano, et al., 2002; Hernández \& Barrera, 2010; Balaguera-López, 2011; Barrera, et al., 2011; Balaguera-López \& Herrera, 2012). Es posible que exista en Colombia el género Amomyrtella, del que se encontró una especie recientemente en Ecuador (Landrum \& Morocho, 2011), el cual se asemeja a algunas especies colombianas de Myrcianthes (Parra-O., 2012). Además, se han encontrado individuos de Blepharocalyx eggersii (Kiaerskou) Landrum en el norte de Brasil, muy cerca de la frontera con Colombia (Landrum, 1986), por lo que es posible que el género también se encuentre en nuestros bosques amazónicos. No obstante, hasta el momento no se han encontrado en las colecciones de herbario especímenes de estos dos géneros recolectados en Colombia.

\section{Calycolpus O. Berg}

Este género posee 15 especies que se distribuyen desde Centroamérica hasta Brasil (Landrum, 2008, 2010). En Colombia crecen dos especies que se reconocen por su cáliz abierto con cinco sépalos y por poseer flores solitarias o inflorescencias en racimos muy cortos con solo dos flores que parecen adyacentes; además, el género se caracteriza por presentar ovario con dos a seis lóculos, testa de la semilla lisa y lustrosa con células isodiamétricas y embrión mirtoide (Landrum \& Kawasaki, 1997; Landrum, 2008, 2010).

\section{Calycorectes O. Berg}

Este género presenta problemas de delimitación y algunos autores consideran que debe incluirse dentro de Eugenia (Landrum \& Kawasaki, 1997; Holst, 2003a). Si se lo considera como género separado de Eugenia, posee cerca de 13 especies distribuidas en México y en un área que va desde Colombia hasta la provincia de Corrientes en Argentina (Legrand \& Klein, 1972; Rotman, 1982). El género se caracteriza por tener el cáliz cerrado o escasamente abierto, con cuatro a seis lóbulos pequeños, regulares o irregulares, inflorescencias cortamente racemosas que asemejan fascículos, hipanto prolongado sobre la porción superior del ovario, ovario bilocular con tres o más óvulos por lóculo y embrión eugenioide (Rotman, 1982; Holst, 2003a). En Colombia solo se tiene registro de una sola especie de este género.

\section{Calyptranthes Sw.}

Este género está compuesto por cerca de 100 especies distribuidas desde el estado de Florida en Estados Unidos hasta Centroamérica y las Antillas, y desde el noreste de Suramérica hasta el norte de Argentina y Uruguay (McVaugh, 1958; McVaugh, 1963; Sánchez-Vindas, 1990). En Colombia crecen entre 23 y 25 especies distribuidas principalmente en la Amazonia, las cuales frecuentemente poseen pelos en forma de T, cáliz cerrado y caliptrado en el que la caliptra se desprende claramente como una unidad en la antesis, inflorescencias en panículas pareadas (algunas veces reducidas), a menudo terminales, ovario con 2(-3) lóculos y embrión mircioide (Landrum \& Kawasaki, 1997; Holst, 2002; Parra-O., 2004a). Lucas, et al., (2011) hicieron un análisis filogenético de Myrcia s.l. y de los géneros relacionados con base en marcadores moleculares y encontraron que, aunque Calyptranthes es un grupo monofilético, está incluido dentro de Myrcia. Con base en el análisis anterior, Lucas, et al., (2011) propusieron que Calyptranthes, Gomidesia O. Berg y Marlierea debían ser parte de Myrcia, y no seguir considerándose como géneros diferentes. Lucas \& Sobral (2011) propusieron conservar el nombre Myrcia en lugar de Calyptranthes para hacer los cambios de nomenclatura necesarios si se acepta que Calyptranthes, Gomidesia y Marlierea deben ser incluidos en Myrcia. Como las propuestas de Lucas, et al., (2011) y Lucas \& Sobral (2011) todavía no han sido formalizadas, en este trabajo Calyptranthes y Marlierea se siguen considerando como otros géneros diferentes de Myrcia.

\section{Campomanesia Ruiz \& Pav.}

Con 25 especies, este género suramericano crece en Trinidad, y desde Colombia hasta el norte de Argentina (Landrum, 1986). En Colombia hay una sola especie del género que se reconoce por su cáliz abierto con cinco sépalos y por tener flores solitarias; además, el género se caracteriza por presentar ovario con (3) 4-18- lóculos, de cuatro a 20 óvulos por lóculo, biseriados, una a cuatro semillas por fruto y embrión mirtoide (Landrum \& Kawasaki, 1997; Landrum, 2003a).

\section{Eugenia L.}

Este es uno de los géneros más diversos de las mirtáceas, con aproximadamente 900 especies distribuidas desde Florida hasta Centroamérica, las Antillas, Suramérica, África y el sureste de Asia (Barrie, 2009). En Colombia se conocen actualmente 42 especies, pero se estima que pueden existir al menos 60 en el territorio nacional. Las especies de Eugenia en Colombia se caracterizan por poseer flores solitarias o en racimos, fascículos o glomérulos, cáliz abierto en el botón floral con cuatro sépalos bien diferenciados, ovario con dos lóculos, frutos con una a dos semillas y embrión eugenioide (Sánchez-Vindas, 1990; Landrum \& Kawasaki, 1997; Parra-O., 2011a). 


\section{Marlierea Cambess.}

En sentido estricto, este género tiene alrededor de 100 especies distribuidas en las Antillas, Panamá y el este de los Andes suramericanos (Holst, 2003b). Sin embargo, el límite genérico entre Marlierea y algunas especies de Myrcia siempre ha sido difícil de establecer, por lo que se discute si debe mantenérselo aparte de Myrcia (Landrum \& Kawasaki, 1997; Holst, 2003b). Lucas, et al., (2011) propusieron considerar a Marlierea y a otros géneros como parte de Myrcia, y no seguir tratándolos como géneros aparte (ver la discusión en torno a Calyptranthes). En Colombia crecen entre seis y ocho especies de Marlierea s. str., distribuidas principalmente en la Amazonia y en áreas de la Orinoquia aledañas a reductos del Escudo Guayanés; generalmente, estas especies se reconocen por tener cáliz cerrado que en la antesis se rasga longitudinalmente en lóbulos irregulares o relativamente regulares, inflorescencias en panículas (algunas veces reducidas) y a menudo pareadas, ovario con 2(-3) lóculos y embrión mircioide (Holst, 2003b; Rosário \& Secco, 2006).

\section{Myrcia DC. ex Guill.}

Este género de distribución neotropical tiene en sentido estricto aproximadamente 350 especies y crece desde México y el Caribe hasta el norte de Argentina (Landrum \& Kawasaki, 1997; Holst, 2003c; Lucas \& Sobral, 2011). En Colombia crecen actualmente 27 especies, pero se estima que pueden existir al menos 35 especies en el territorio nacional. El género se caracteriza por tener el cáliz abierto con cinco sépalos (raramente cuatro) bien diferenciados, inflorescencias en panículas, ovario con 2-3 (4)- lóculos, dos óvulos por lóculo, generalmente una a dos semillas y embrión mircioide (Landrum \& Kawasaki, 1997; Holst, 2003c). Gomidesia O. Berg, reportado ocasionalmente para Colombia, fue descrito como un género afín a Myrcia pero distinto de este; en la actualidad, se acepta que Gomidesia debe ser parte de Myrcia y algunos autores lo consideran como una sección dentro del primero (Lucas, et al., 2007; Lughadha, et al., 2010; Lucas, et al., 2011).

\section{Myrcianthes O. Berg}

Este género consta de 30 a 35 especies, distribuidas en el sur de Florida, el Caribe y México hasta Chile (Grifo, 1992; Landrum \& Kawasaki, 1997; Proença, et al., 2011; Parra-O., 2012). En Colombia se encuentran entre 12 y 13 especies, que crecen principalmente en la cordillera de los Andes entre 1.800 y 3.500 metros. Las especies de este género se reconocen por poseer hojas frecuentemente coriáceas, generalmente inflorescencias en dicasios regular o irregularmente ramificados y raramente flores solitarias, cáliz abierto en el botón floral con cuatro sépalos bien diferenciados (raramente cinco), ovario usualmente con dos lóculos (a veces tres), cinco a 30 óvulos por lóculo, generalmente frutos con una a dos semillas (a veces hasta cuatro) y embrión con dos cotiledones plano-convexos y separados (Landrum \& Kawasaki, 1997; Proença, et al., 2011; Parra-O., 2012).

\section{Myrciaria O. Berg}

Comprende 15 a 20 especies que crecen en Centroamérica, las islas del Caribe y el este de los Andes en Suramérica (Sobral, 1993; Holst, 2003d). El género se caracteriza por presentar flores agrupadas generalmente en glomérulos que poseen el hipanto extendido más allá del ovario, el cual cae en conjunto con el cáliz como una sola unidad después de la antesis; además, presenta bractéolas connatas en el tercio inferior, cáliz abierto en el botón floral con cuatro sépalos y embrión eugenioide con los cotiledones soldados (Sobral, 1993; Landrum \& Kawasaki, 1997; Holst, 2003d). En Colombia crecen tres especies, distribuidas en la mayoría de regiones biogeográficas del país.

\section{Myrrhinium Schott}

Este género monotípico se caracteriza por poseer inflorescencias en dicasios simples (que a su vez se disponen agregados en racimos), flores tetrámeras, cáliz abierto con cuatro sépalos, pétalos rosados con apéndices setosos en la base, cuatro a ocho estambres por flor, erectos, rígidos y de color rojo, ovario con dos lóculos y embrión mirtoide (Landrum, 1986; Landrum \& Kawasaki, 1997; Parra-O., 2003). Myrrhinium atropurpureum, con dos variedades, se distribuye en Suramérica en Brasil, Uruguay y a lo largo de los Andes desde Argentina hasta Colombia (Landrum, 1986); en Colombia crece $M$. atropurpureum Schott var. octandrum Benth. (Parra-O., 2003).

\section{Myrteola O. Berg}

Este género presenta tres especies distribuídas desde Venezuela y Colombia hasta Chile (incluidas las islas Malvinas y Juan Fernández; Landrum, 1988). En Colombia se encuentran dos especies que crecen en los Andes entre los 2.300 y 3.500 metros. El género se caracteriza por poseer hojas coriáceas, cáliz abierto con cuatro sépalos bien diferenciados, flores solitarias y erectas, estambres exsertos, ovario con dos a tres lóculos y embrión mirtoide (Landrum, 1988; Landrum, 2003b).

\section{Plinia L.}

Este género tiene cerca de 40 especies distribuidas en las Antillas occidentales, Cuba, Centroamérica y Suramérica, excepto Chile (Landrum, 1998; Barrie, 2004; Kawasaki \& Pérez, 2012). Se reconoce por poseer cáliz cerrado o casi cerrado que se separa en la antesis en cuatro lóbulos irregulares, inflorescencias generalmente en glomérulos, hipanto prolongado más allá de la porción superior del ovario, óvulo bilocular con dos óvulos por lóculo, frutos con una o varias semillas y embrión con dos cotiledones planoconvexos y separados con hipocótilo reducido (Barrie, 2004; 
Kawasaki \& Pérez, 2012). En Colombia se encuentran entre tres y cuatro especies que crecen desde la Amazonia hasta la zona Andina.

\section{Pseudanamomis Kausel}

Este género monoespecífico distribuido en las Antillas, Colombia, Venezuela, Trinidad y la Guayana (Grifo, 2003) se caracteriza por presentar el ápice de la lámina foliar retuso o emarginado, los lóbulos del cáliz caedizos, las inflorescencias en dicasios simples que frecuentemente desarrollan flores adicionales (asemejándose a una umbela) y los cotiledones parcialmente fusionados (Grifo, 1992, 2003). En Colombia Pseudanamomis umbellulifera (Kunth) Kausel crece en zonas semidesérticas de la costa Caribe (Guajira) a 200 metros de altitud (Parra-O., 2012).

\section{Psidium L.}

Se reconocen en este género al menos 50 especies, pero se estima que podría tener cerca de 100 distribuidas naturalmente en el Caribe, y desde México hasta Argentina y Uruguay (Landrum \& Sobral, 2006; Landrum \& Funch, 2008; Soares-Silva \& Proença, 2008). En Colombia crecen entre 12 y 13 especies del género que se reconocen, entre otros, por tener cáliz cerrado (a veces formando una caliptra) que en la antesis se rasga en lóbulos irregulares o relativamente regulares, o cáliz abierto con cinco sépalos, flores solitarias o en dicasios generalmente simples (raramente compuestos) u ocasionalmente en racimos; además, el género se caracteriza por presentar en el ovario lóculos con numerosos óvulos, pocas o numerosas semillas con la testa ósea cubierta con una capa pulposa y embrión mirtoide (Landrum \& Kawasaki, 1997; Landrum, 2003c; Landrum, 2003e).

\section{Ugni Turcz.}

Con cuatro especies, este género se distribuye desde México hasta Chile (Landrum \& Kawasaki, 1997; Rosário, et al., 2004). La única especie del género que crece en Colombia ( $U$. myricoides (Kunth) O. Berg) se caracteriza por poseer hojas coriáceas, cáliz abierto con cinco sépalos bien diferenciados, flores solitarias que se doblan y apuntan hacia abajo, corola campanulada, estambres no prolongados más allá del borde de la corola, ovario usualmente con tres lóculos, frutos con 15 a 20 semillas y embrión mirtoide (Landrum \& Kawasaki, 1997; Landrum, 2003d).

\section{Clave para la identificación de los géneros de Myrtaceae presentes en Colombia}

Esta clave incluye tanto los géneros de Myrtaceae nativos de Colombia, como los que han sido introducidos al país. En la clave se señalan con asterisco $(*)$ los géneros introducidos.

1. Frutos en cápsulas; plantas exclusivamente cultivadas ..... 2

1.’ Frutos en baya; plantas cultivadas o nativas ... 6
2. Sépalos fusionados unos con otros en el botón floral (cáliz cerrado) y caliptrados; inflorescencias en umbelas simples o en umbelas simples dispuestas en racimos ........................... 3

2.' Sépalos libres en el botón floral; flores solitarias, inflorescencias en espigas o muy ramificadas en las que los ejes secundarios terminan en cimas con tres flores ....................... 4

3. Inflorescencias en umbelas a su vez dispuestas en racimos o en panículas terminales; frutos ... Corymbia*

3.' Inflorescencias en umbelas axilares a las hojas; frutos ovoides o globulares pero nunca urceolados ........ Eucalyptus*

4. Hojas alternas; inflorescencias en espigas con numerosas flores Melaleuca*

4.' Hojas alternas u opuestas; flores solitarias o inflorescencias muy ramificadas en las que los ejes secundarios terminan en cimas con tres flores 5

5. Hojas alternas; lámina foliar con el envés concóloro o discóloro, pero no grisáceo; flores solitarias .

Leptospermum*

5.' Hojas opuestas; lámina foliar con el envés grisáceo; inflorescencias muy ramificadas en las que los ejes secundarios terminan en cimas con tres flores Metrosideros*

6. Sépalos fusionados unos con otros en el botón floral (cáliz cerrado), que se desprenden en la antesis como una caliptra o se rasgan en lóbulos irregulares o relativamente regulares; parte superior de los frutos con una cicatriz anular apical producto del desprendimiento del cáliz ... 7

6.' Sépalos libres en el botón floral (cáliz abierto) en el que los sépalos se diferencian claramente unos de otros; parte superior de los frutos con los restos de los sépalos del cáliz claramente diferenciados, sin cicatriz anular ...................... 11

7. Inflorescencias en panículas; embrión de tipo mircioide .... 8

7.' Flores solitarias o inflorescencias en fascículos, glomérulos o dicasios generalmente simples u ocasionalmente compuestos; embrión de tipo eugenioide o mirtoide ........... 9

8. Cáliz cerrado en el botón floral que en la antesis se desprende claramente como una unidad (caliptra) Calyptranthes

8.' Cáliz cerrado en el botón floral que en la antesis se rasga longitudinalmente en lóbulos irregulares o relativamente regulares Marlierea

9. Inflorescencias en fascículos o glomérulos; hipanto prolongado sobre o más allá de la porción superior del ovario; semillas con la testa cartácea o ligeramente coriácea .......... 10

9.' Flores solitarias o dicasios generalmente simples u ocasionalmente compuestos; hipanto no prolongado sobre o más allá de la porción superior del ovario; semillas con la testa ósea Psidium 
10. Inflorescencias en fascículos; ovario bilocular con tres o más óvulos por lóculo; embrión eugenioide (con los cotiledones fusionados y sin distinción del hipocótilo) ........ Calycorectes

10.' Inflorescencias en glomérulos; ovario bilocular con dos óvulos por lóculo; embrión con dos cotiledones planoconvexos y separados con hipocótilo reducido Plinia

11. Subarbustos erectos o postrados; láminas foliares siempre coriáceas; flores siempre solitarias; embrión exclusivamente mirtoide; plantas nativas que crecen principalmente en el subpáramo o páramo

11.' Arboles, arbolitos o arbustos, ocasionalmente subarbustos; láminas foliares cartáceas o coriáceas; flores solitarias, en racimos (cortos o largos), fascículos, glomérulos, dicasios (a veces agregados en racimos o con flores adiciones, y que lucen como umbelas) o panículas; embrión mircioide, eugenioide o mirtoide; plantas cultivadas o nativas, estas últimas crecen en diferentes ecosistemas del gradiente altitudinal . .. 13

12. Cáliz floral con cinco sépalos bien diferenciados; flores que se doblan y apuntan hacia abajo; corola campanulada; estambres no prolongados más allá del borde de la corola ..... Ugni

12.' Cáliz floral con cuatro sépalos bien diferenciados, flores erectas; corola no campanulada; estambres exsertos

Myrteola

13. Lóbulos del cáliz siempre en número de cuatro (observados en el botón floral o como remanentes en la parte superior del fruto)

13.' Lóbulos del cáliz siempre en número de cinco (observados en el botón floral o como remanentes en la parte superior del fruto) . .23

14. Inflorescencias en panículas 15

14.' Flores solitarias, en racimos (cortos o largos), fascículos, glomérulos o dicasios (a veces agregados en racimos o con flores adiciones y que lucen como umbelas), nunca en panículas 17

15. Frutos nunca piriformes ni rosados, generalmente globosos o elipsoides; embrión mircioide o mirtoide; plantas nativas o cultivadas

15.' Frutos piriformes rosados o elipsoides negruzcos; embrión similar al eugenioide pero con los cotiledones divididos; plantas exclusivamente cultivadas Syzygium*

16. Hojas escasa a moderadamente aromáticas; ovario con dos lóculos; embrión mircioide; plantas nativas ......... Myrcia

16.’ Hojas muy aromáticas; ovario con un solo lóculo; embrión mirtoide; plantas exclusivamente cultivadas

Pimenta*
17. Inflorescencias en dicasios simples agregados en racimos; pétalos rosados con apéndices setosos en la base; 4-8 estambres por flor, erectos, rígidos y de color rojo .......... Myrrhinium

17.' Flores solitarias, en racimos (cortos o largos), fascículos, glomérulos o dicasios (a veces con flores adiciones y que lucen como umbelas); pétalos blancos o rosados sin apéndices setosos en la base; numerosos estambres por flor (más de 10) erectos o no, generalmente de color blanco 18

18. Lámina foliar con el envés grisáceo; pétalos carnosos con margen fuertemente involuta, de color rosado a púrpura por la haz; filamentos de los estambres de color rojo; semillas con embrión mirtoide Acca* $^{*}$

18’. Lámina foliar que nunca exhibe el envés grisáceo; pétalos no carnosos con margen plana o ligeramente involuta, de color blanco o rosado por la haz; filamentos de los estambres de color blanco o rosado; semillas con embrión eugenioide o similar al eugenioide pero con los cotiledones divididos

19. Estambres siempre de color rosado; plantas exclusivamente cultivadas Syzygium*

19.' Estambres siempre de color blanco; plantas generalmente nativas, raramente cultivadas 20

20. Inflorescencias en glomérulos; flores con el hipanto extendido más allá del ovario, el cual cae en conjunto con el cáliz, como una sola unidad, después de la antesis; bractéolas connatas en el tercio inferior Myrciaria

20.’ Flores solitarias, en racimos (cortos o largos), fascículos o dicasios (a veces con flores adiciones y que lucen como umbelas); flores sin el hipanto extendido más allá del ovario, el cual no se desprende después de la antesis; bractéolas connatas en la base o libres 21

21. Ápice de la lámina foliar exclusivamente retuso o emarginado; lóbulos del cáliz caedizos; inflorescencias en dicasios simples que frecuentemente desarrollan flores adicionales semejantes a umbelas; cotiledones parcialmente fusionados; plantas que crecen exclusivamente en zonas semidesérticas de la costa Caribe (Guajira).

Pseudanamomis

21.’ Ápice de la lámina foliar agudo, obtuso, retuso o emarginado; lóbulos del cáliz persistentes; flores solitarias o inflorescencias en racimos, fascículos o dicasios (que no desarrollan flores adicionales asemejando umbelas); cotiledones totalmente fusionados o separados; plantas que crecen en diferentes regiones naturales de Colombia

22

22. Flores solitarias o inflorescencias en racimos o fascículos; embrión con los cotiledones completamente fusionados en una sola masa y sin distinción del hipocótilo Eugenia 
22.' Inflorescencias en dicasios simples o compuestos (raramente flores solitarias); embrión con los cotiledones separados e hipocótilo diferenciable Myrcianthes

23. Inflorescencias en panículas 24

23.' Flores solitarias o inflorescencias en racimos cortos, fascículos o dicasios (a veces con flores adiciones y que lucen como umbelas)

24. Hojas poco a moderadamente aromáticas; ovario con dos lóculos; embrión mircioide; plantas nativas . Myrcia

24.’ Hojas muy aromáticas; ovario con un solo lóculo; embrión mirtoide; plantas exclusivamente cultivadas Pimenta*

25. Inflorescencias en dicasios simples o compuestos Myrcianthes

25.' Flores solitarias o inflorescencias en racimos cortos, fascículos o dicasios que tienen flores adiciones y lucen como umbelas (nunca dicasios simples o compuestos)...... 26

26. Semillas con la testa ósea cubierta con una capa pulposa en fresco; embrión exclusivamente mirtoide . .Psidium

26.' Semillas con la testa membranosa o ligeramente dura, pero nunca ósea, y sin capa pulposa; embrión con los cotiledones parcialmente fusionados o mirtoide 27

27. Ápice de la lámina foliar exclusivamente retuso o emarginado; lóbulos del cáliz caedizos; inflorescencias en dicasios simples que frecuentemente desarrollan flores adicionales que semejan umbelas; cotiledones parcialmente fusionados; plantas que crecen exclusivamente en zonas semidesérticas de la costa Caribe (Guajira) Pseudanamomis

27.’ Ápice de la lámina foliar agudo u obtuso; lóbulos del cáliz persistentes; flores solitarias o inflorescencias en racimos cortos; embrión de tipo mirtoide; plantas cultivadas o que crecen naturalmente en diferentes regiones naturales de Colombia 28

28. Plantas de hábito arbustivo; ápice de la lámina foliar acuminado con mucrón evidente; ancho del pedicelo floral menor o igual a 0,4 mm; plantas exclusivamente cultivadas ... Myrtus*

28.' Plantas de hábito arbóreo; ápice de la lámina foliar caudado o ligeramente atenuado sin mucrón evidente; ancho del pedicelo floral mayor o igual a $0,6 \mathrm{~mm}$; plantas nativas que ocasionalmente pueden ser cultivadas (i.e., Campomanesia)

29. Vena marginal de la lámina foliar claramente diferenciable, paralela a la margen de la lámina; lámina foliar elíptica u oblanceolada, fruto no mayor a 1,3 cm de diámetro en la madurez Calycolpus

29.' Vena marginal de la lámina foliar no diferenciable; lámina foliar anchamente ovada; fruto de cerca de $7 \mathrm{~cm}$ de diámetro en la madurez Campomanesia

\section{Conflicto de interés}

El autor declara que no tiene conflicto de interés.

\section{Agradecimientos}

A los herbarios CAS, CAUP, COAH, COL, CUVC, FMB, GH, HUA, JAUM, LLANOS, MEDEL, MICH, MO, NY, PSO, SURCO, TOLI, US y UTMC por permitir el acceso a sus colecciones. Al Jardín Botánico de Missouri (Estados Unidos) y a su programa de becas "Alwyn H. Gentry” para Estudios en Botánica Suramericana, por permitir mi estadía y trabajo en esa institución como investigador visitante en taxonomía de Myrtaceae colombianas (junio a julio del 2003). A la Academia de Ciencias de California - Herbario CAS (Estados Unidos) y al programa de becas de la Fundación Lakeside, por permitir mi estadía y trabajo en esa institución como investigador visitante en taxonomía y sistemática de Myrtaceae colombianas (abril de 2013). A la Asociación Colombiana de Herbarios (ACH) por su invitación a la gira de especialistas entre 2013 y 2014 para revisar material de Myrtaceae en diferentes herbarios colombianos. A María Fernanda González, Lauren Raz y Betsy Viviana Rodríguez, por permitir el uso de fotos selectas de Myrtaceae en este artículo. A Marcela Morales por algunas de las ilustraciones que acompañan este artículo. A los dos evaluadores anónimos por sus comentarios y sugerencias que ayudaron a enriquecer el manuscrito. Agradezco especialmente al Herbario Nacional Colombiano (COL) - Instituto de Ciencias Naturales - Universidad Nacional de Colombia por todo el apoyo recibido.

\section{Bibliografía}

Balaguera-López, H. 2011. Estudio del crecimiento y desarrollo del fruto de champa (Campomanesia lineatifolia Ruiz \& Pav.) y determinación del punto óptimo de cosecha. Tesis de Maestría, Facultad de Agronomía, Universidad Nacional de Colombia. 138 p.

Balaguera-López, H. \& A. Herrera. 2012. Determining optimal harvest point for champa (Campomanesia lineatifolia Ruiz \& Pav.) fruit based on skin color. Ingeniería e Investigación. 32 (1): 88-93.

Baptiste, M. P., N. Castaño, D. Cárdenas, F. Gutiérrez, D. Gil \& C. Lasso. (eds.). 2010. Análisis de riesgo y propuesta de categorización de especies introducidas para Colombia. Instituto de Investigación de Recursos Biológicos Alexander von Humboldt. Bogotá.

Barrera, J., Hernández, M. \& L. Melgarejo. (comp.). 2011. Estudios ecofisiológicos en la Amazonia colombiana 1. Arazá (Eugenia stipitata, McVaugh). Instituto Amazónico de Investigaciones Científicas - Sinchi, Bogotá.

Barrie, F. 2004. Synopsis of Plinia (Myrtaceae) in Mesoamerica. Novon 14: 380-400. 
Barrie, F. 2009. Eugenia. Págs.: 81-129. En: G. Davidse, M. Sousa, S. Knapp, F. Chiang \& F. Barrie (eds.). Flora Mesoamericana. Volumen 4, parte 1, Cucurbitaceae a Polemoniaceae. Universidad Nacional Autónoma de México - Missouri Botanical Garden - The Natural History Museum (London).

Berg, O. 1855-1856. Revisio Myrtacearum Americae. Linnaea 27: $1-472$.

Berg, O. 1857-1859. Myrtaceae. En: C. F. P. von Martius. Flora Brasiliensis 14 (1): 1-655.

Bernal, R., M. Celis \& R. Gradstein. 2007. Plant diversity of Colombia catalogued. Taxon 56 (1): 273.

Chantaranothai, P. \& J. Parnell. 1994. A revision of Acmena, Cleistocalyx, Eugenia s.s. and Syzygium (Myrtaceae) in Thailand. Thai For. Bull. 21: 1-123.

Chippendale, G. M. 1988. Eucalyptus. Págs. 1-448. En: A. George (ed.). Flora of Australia. Volume 19. Myrtaceae, Eucalyptus, Angophora. Australian Government Publishing Service, Canberra.

Craven, L. 2006. New combinations in Melaleuca for Australian species of Callistemon. Novon 16: 468-475.

Díaz-Espinosa, A., J. Díaz-Triana \& O. Vargas (eds.). 2012. Catálogo de plantas invasoras de los humedales de Bogotá. Grupo de Restauración Ecológica de la Universidad Nacional de Colombia y Secretaría Distrital de Ambiente. Bogotá.

Graham, S. 2004. Alzateaceae. Págs. 11-13. En: Smith, N., S. Mori, A. Henderson, D. Stevenson \& S. Heald (eds.). Flowering Plants of the Neotropics. The New York Botanical Garden Princeton University Press. New York.

Grifo, F. 1992. A revision of Myrcianthes Berg (Myrtaceae). Disertación doctoral, Cornell University, Ithaca, Nueva York (inédita).

Grifo, F. 2003. Pseudanamomis. Págs. 87-88. en: J. Steyermark, P. Berry, K. Yatskievych \& B. Holst (eds.). Flora of the Venezuelan Guayana. Volume 7. Myrtaceae-Plumbaginaceae. Missouri Botanical Garden Press, St. Louis.

Hernández, M. \& J. Barrera (comp.). 2010. Camu camu. Instituto Amazónico de Investigaciones Científicas - Sinchi, Bogotá.

Hill, K. D. \& Johnson, L. A. S. 1995. Systematic studies in the eucalypts 7. A revision of the bloodwoods, genus Corymbia (Myrtaceae). Telopea 6: 185-504.

Holst, B. 2002. New species and notes on Myrtaceae from Northern South America. Selbyana 23 (2): 137-180.

Holst, B. 2003a. Calycorectes. Págs. 8-9. en: J. Steyermark, P. Berry, K. Yatskievych \& B. Holst (eds.). Flora of the Venezuelan Guayana. Volume 7. Myrtaceae-Plumbaginaceae. Missouri Botanical Garden Press, St. Louis.

Holst, B. 2003b. Marlierea. Págs. 40-53. En: J. Steyermark, P. Berry, K. Yatskievych \& B. Holst (eds.). Flora of the Venezuelan Guayana. Volume 7. Myrtaceae-Plumbaginaceae. Missouri Botanical Garden Press, St. Louis.
Holst, B. 2003c. Myrcia. Págs. 54-78. En: J. Steyermark, P. Berry, K. Yatskievych \& B. Holst (eds.). Flora of the Venezuelan Guayana. Volume 7. Myrtaceae-Plumbaginaceae. Missouri Botanical Garden Press, St. Louis.

Holst, B. 2003d. Myrciaria. Págs. 81-84. En: J. Steyermark, P. Berry, K. Yatskievych \& B. Holst (eds.). Flora of the Venezuelan Guayana. Volume 7. Myrtaceae-Plumbaginaceae. Missouri Botanical Garden Press, St. Louis.

Kawasaki, M. L. \& A. Pérez. 2012. A new species of Plinia (Myrtaceae) from Ecuador, with demographic notes from a large forest plot. Harvard Papers in Botany 17 (1): 19-20.

Ladiges, P., F. Udovicic \& G. Nelson. 2003. Australian biogeographical connections and the phylogeny of large genera in the plant family Myrtaceae. Journal of Biogeography 30: 989-998.

Landrum, L. 1984. Taxonomic implications of the discovery of calyptrate species of Myrceugenia (Myrtaceae). Brittonia 36 (2): 161-166

Landrum, L. 1986. Campomanesia, Pimenta, Blepharocalyx, Legrandia, Acca, Myrrhinium, and Luma (Myrtaceae). Flora Neotrop. Monogr. 45: 1-179.

Landrum, L. 1988. Systematics of Myrteola (Myrtaceae). Systematic Botany 13 (1): 120-132.

Landrum, L. 1990. Accara: A New Genus of Myrtaceae, Myrtinae from Brazil. Systematic Botany 15 (2): 221-225.

Landrum, L. 1991. Chamguava: A New Genus of Myrtaceae (Myrtinae) from Mesoamerica. Systematic Botany 16 (1): 21-29.

Landrum, L. 2003a. Campomanesia. Págs. 16-17. En: J. Steyermark, P. Berry, K. Yatskievych \& B. Holst (eds.). Flora of the Venezuelan Guayana. Volume 7. MyrtaceaePlumbaginaceae. Missouri Botanical Garden Press, St. Louis.

Landrum, L. 2003b. Myrteola. Págs. 84-85. En: J. Steyermark, P. Berry, K. Yatskievych \& B. Holst (eds.). Flora of the Venezuelan Guayana. Volume 7. Myrtaceae-Plumbaginaceae. Missouri Botanical Garden Press, St. Louis.

Landrum, L. 2003c. Psidium. Págs. 88-95. En: J. Steyermark, P. Berry, K. Yatskievych \& B. Holst (eds.). Flora of the Venezuelan Guayana. Volume 7. Myrtaceae-Plumbaginaceae. Missouri Botanical Garden Press, St. Louis.

Landrum, L. 2003d. Ugni. Págs. 98-99. En: J. Steyermark, P. Berry, K. Yatskievych \& B. Holst (eds.). Flora of the Venezuelan Guayana. Volume 7. Myrtaceae-Plumbaginaceae. Missouri Botanical Garden Press, St. Louis.

Landrum, L. 2003e. A revision of the Psidium salutare complex (Myrtaceae). Sida 20 (4): 1449-1469.

Landrum, L. 2008. Two new species of Calycolpus (Myrtaceae) from Brazil. Brittonia 60 (3): 252-256.

Landrum, L. 2010. A revision of Calycolpus (Myrtaceae). Systematic Botany 35 (2): 368-389. 
Landrum, L. \& M. L. Kawasaki. 1997. The genera of Myrtaceae in Brazil: An illustrated synoptic treatment and identification keys. Brittonia 49 (4): 508-536.

Landrum, L. \& M. Sobral. 2006. Psidium cauliflorum (Myrtaceae), a new species from Bahia, Brazil. Sida 22 (2): 927-929.

Landrum, L. \& L. Funch. 2008. Two new species of Psidium (Myrtaceae) from Bahia, Brazil. Novon 18: 74-77.

Landrum, L. \& V. Morocho. 2011. A new combination based on Myrcianthes irregularis (Myrtaceae) - A new genus for Ecuador. Journal of the Botanical Research Institute of Texas 5 (1): 105-107.

Legrand, D. \& R. Klein. 1972. Flora Ilustrada Catarinense. Mirtáceas: Calycorectes Berg [MIRT] 7: 553-569.

Lozano, J., J. Toro, R. García \& R. Tafur. 2002. Manual sobre el cultivo del guayabo en Colombia. Fruticultura colombiana. Litografía Autónoma del Valle Lavalle Ltda, Cali.

Lucas, E., S. Harris, F. Mazine, S. Belsham, E. Nic Lughadha, A. Telford, P. Gasson \& M. Chase. 2007. Suprageneric phylogenetics of Myrteae, the generically richest tribe in Myrtaceae (Myrtales). Taxon 56: 1105-1128.

Lucas, E. \& M. Sobral. 2011. Proposal to conserve the name Myrcia against Calyptranthes (Myrtaceae). Taxon 60 (2): 605.

Lucas, E., K. Matsumoto, S. Harris, E. Lughadha, B. Benardini \& M. Chase. 2011. Phylogenetics, morphology, and evolution of the large genus Myrcia s.l. (Myrtaceae). International Journal of Plant Sciences 172 (7): 915-934.

Lughadha, N., K. Slade, L. Jennings, H. Boudet-Fernandes \& E. Lucas. 2010. Three new species of Myrcia section Gomidesia (Myrtaceae) - from Espírito Santo, Brazil. Kew Bulletin 65: 21-28.

Mabberley, D. 2008. Mabberley’s plant book. A portable dictionary of the higher plants. Tercera edición. Cambridge University Press. Cambridge.

McVaugh, R. 1956. Tropical American Myrtaceae, I - Notes on generic concepts and description of previously unrecognized species. Fieldiana, Bot. 29 (3): 145-228.

McVaugh, R. 1958. Myrtaceae. En: Maguire, J. F. (Ed.), Flora of Peru. Field Mus. Nat. Hist., Bot Ser. 13 part 4 (2): 569-818.

McVaugh, R. 1963. Myrtaceae. En: Flora de Guatemala. Fieldiana, Bot. 24 part 7 (3): 283-405.

McVaugh, R. 1968. The genera of American Myrtaceae - An interim report. Taxon 17: 354-418.

McVaugh, R. 1969. Myrtaceae. En: Maguire, B. \& Wurdack, J.J. (Eds.), The Botany of the Guayana Highlands, part. VIII. Mem. New York Bot. Gard. 18: 55-286.

Parra-O., C. 2001. Una nueva especie de Calyptranthes Sw. (Myrtaceae) de Colombia. Caldasia 23 (2): 435-439.

Parra-O., C. 2002. Dos nuevas especies de Myrtaceae de Colombia. Caldasia 24 (1): 95-102.
Parra-O., C. 2003. Redescubrimiento de Myrrhinium atropurpureum var. octandrum (Myrtaceae: Myrtinae) en Colombia. Caldasia 25 (2): 229-233.

Parra-O., C. 2004a. New taxa of Calyptranthes (Myrtaceae) from Colombia. Novon 14 (2): 210-215.

Parra-O., C. 2004b. Myrtaceae. Págs. 333-334. En: J. O. RangelCh. (ed.). Colombia Diversidad Biótica IV - El Chocó biogeográfico/Costa Pacífica. Instituto de Ciencias Naturales, Universidad Nacional de Colombia, Bogotá.

Parra-O., C. 2004c. Primer registro de Calyptranthes cuspidata (Myrtaceae: Myrciinae) para Colombia. Caldasia 26 (1): 323-326.

Parra-O., C. 2011a. Una nueva especie de Eugenia (Myrtaceae) de Colombia. Caldasia 33 (2): 407-411.

Parra-O., C. 2011b. Myrtaceae. Págs. 644-649. En: A. Idárraga, R. del C. Ortiz, R. Callejas \& M. Merello (eds.). Flora de Antioquia: catálogo de las plantas vasculares. vol. II. Listado de las plantas vasculares del departamento de Antioquia. Programa Expedición Antioquia-2013. Series Biodiversidad y Recursos Naturales. Universidad de Antioquia, Missouri Botanical Garden \& Oficina de planeación departamental de la Gobernación de Antioquia, Editorial D’Vinni, Bogotá.

Parra-O., C. 2012. Una nueva especie de Myrcianthes (Myrtaceae) de Colombia. Caldasia 34 (2): 277-282.

Parra-O., C. 2013. Una nueva especie de Myrcia (Myrtaceae) y nuevos registros de la familia para Colombia. Caldasia 35 (2): 293-298.

Parra-O., C., M. Bayly, F. Udovicic \& P. Ladiges. 2006. ETS sequences support the monophyly of the eucalypt genus Corymbia (Myrtaceae). Taxon 55 (3): 653-663.

Parra-O., C., M. Bayly, A. Drinnan, F. Udovicic \& P. Ladiges. 2009. Phylogeny, major clades and infrageneric classification of Corymbia (Myrtaceae), based on nuclear ribosomal DNA and morphology. Australian Systematic Botany 22 (5): 384-399.

Pérez-Arbeláez, E. 1996. Plantas útiles de Colombia. Fondo FEN Colombia. Quinta edición. Bogotá.

Proença, C., E. Nic Lughadha, E. Lucas \& E. Woodgyer. 2006. Algrizea (Myrteae, Myrtaceae): A new genus from the highlands of Brazil. Systematic Botany 31 (2): 320-326.

Proença, C., L. Jennings \& E. Lucas. 2011. Two new species of Myrtaceae (Myrteae) from northern South America. Brittonia 63 (1): 46-50.

Rangel-Ch., J. O. 2000. Catálogo florístico de los macizos de Chingaza y Sumapaz. Págs. 563-598. En: J. O. Rangel-Ch. (ed). Colombia Diversidad Biótica III. La región de vida paramuna. Instituto de Ciencias Naturales, Universidad Nacional de Colombia. Unibiblos. Bogotá.

Romero-Castañeda, R. 1991. Frutas silvestres de Colombia. Segunda Edición. Instituto Colombiano de Cultura Hispánica. Bogotá. 
Rosário, A. S., R. S. Secco \& J. B. Silva. 2004. Notas sobre Ugni Turcz. (Myrtacae) na Amazônia Brasileira. Acta Amazonica 34 (1): 139-141.

Rosário, A. S. \& R. S. Secco. 2006. Sinopse das espécies de Marlierea Cambess. (Myrtaceae) na Amazonia brasileira. Acta Amazonica 36 (1): 37-52.

Rotman, A. 1982. Los géneros Calycorectes, Hexachlamys, Myrciaria, Paramyrciaria, Plinia y Siphoneugena en la flora argentina (Myrtaceae). Darwiniana 24 (1-4): 157-185.

Rudas, A. \& A. Prieto. 2005. Flórula del Parque Nacional Natural Amacayacu. Monographs in Systematic Botany from the Missouri Botanical Garden 99: 1-680. Missouri Botanical Garden Press, St. Louis.

Salywon, A. \& L. Landrum. 2007. Curitiba (Myrtaceae): A new genus from the Planalto of southern Brazil. Brittonia 59 (4): 301-307.

Sánchez-Vindas, P. 1990. Myrtaceae. En: Gómez-Pompa, A. (ed.). Flora de Veracruz. Instituto de Ecología, Xalapa, Veracruz, México 62: 1-146.

Schmidt-Adam, G. \& K. Gould. 2000. Phenology of inflorescence development in pohutukawa (Metrosideros excelsa, Myrtaceae). New Zealand Journal of Botany 38: 333-337.

Snow, N., G. Guymer \& G. Sawvel. 2003. Systematics of Austromyrtus, Lenwebbia, and the Australian species of Gossia (Myrtaceae). Systematic Botany Monographs 65: 1-95.
Soares-Silva, L. \& C. Proença. 2008. A new species of Psidium L. (Myrtaceae) from southern Brazil. Botanical Journal of the Linnean Society 158: 51-54.

Sobral, M. 1993. Sinopse de Myrciaria (Myrtaceae). Napaea 9: 13-41.

Thompson, J. \& V. Logan. 1991. Leptospermum. Págs. 154-168. En: Harden, G. (ed.). Flora of New South Wales. Volumen 2. Royal Botanical Gardens Sydney. New South Wales University Press, Kensington.

Weberling, F. 1988. The architecture of inflorescences in Myrtales. Annals of the Missouri Botanical Garden 75: 226-310.

Wilson, P. 1991. Melaleuca. Págs. 173-179. En: Harden, G. (ed.). Flora of New South Wales. Volumen 2. Royal Botanical Gardens Sydney. New South Wales University Press, Kensington.

Wilson, P., M. O’Brien, M. Heslewood \& C. Quinn. 2005. Relationships within Myrtaceae sensu lato based on a matK phylogeny. Plant Systematics and Evolution 251: 3-19.

Wright, S., C. Young, J. Dawson, D. Whittaker \& R. Gardner. 2000. Riding the ice age El Niño? Pacific biogeography and evolution of Metrosideros subg. Metrosideros (Myrtaceae) inferred from nuclear ribosomal DNA. Proceedings of the National Academy of Sciences of United States of America 97 (8): 4118-4123. 